\title{
Evaluating a Breakthrough Series Collaborative in a Swedish Health Care Context
}

\author{
Ann-Christine Andersson, Ewa Idvall, Kent-Inge Perseius and Mattias Elg
}

\section{Linköping University Post Print}

\section{Tweet}

N.B.: When citing this work, cite the original article.

Original Publication:

Ann-Christine Andersson, Ewa Idvall, Kent-Inge Perseius and Mattias Elg, Evaluating a Breakthrough Series Collaborative in a Swedish Health Care Context, 2014, Journal of Nursing Care Quality, (29), 2, E1-E10.

http://dx.doi.org/10.1097/NCQ.0b013e3182a95ff6

Copyright: Lippincott, Williams \& Wilkins

http://www.lww.com/

Postprint available at: Linköping University Electronic Press

http://urn.kb.se/resolve?urn=urn:nbn:se:liu:diva-108940 


\section{Title page}

\section{Evaluating a Breakthrough Series Collaborative in a Swedish healthcare context}

\section{Ann-Christine Andersson (RN, MSc, Ph Lic.)}

Division of Quality Technology and Management, Linköping University, Linköping, Development Department, Kalmar County Council, and Department of Care Science, Faculty of Health and Society, Malmö University, Malmö, Sweden.

Ewa Idvall (Professor, RN) Department of Care Science, Faculty of Health and Society, Malmö University and Department of Intensive Care and Perioperative Medicine, Skåne University Hospital, Malmö, Sweden.

Kent-Inge Perseius (PhD, RN) Nyckeln competence centre for pedagogy in health care, Kalmar County Council, and the Department of Neurobiology, Caring Sciences and Society, Karolinska Institutet, Stockholm, Sweden.

\section{Mattias Elg (Professor)}

Division of Quality Technology and Management and HELIX Vinn Excellence Centre, Linköping University, Linköping, Sweden.

\section{Corresponding author}

Ann-Christine Andersson

Development Department, Kalmar County Council

Box 601

39136 Kalmar

Sweden

contact@ann-christine.se

\section{Funding information}

This study is part of postgraduate studies with financial support from Swedish Association of Local Authorities and Regions, and the Kalmar County Council Research and Development Delegation. 


\section{ABSTRACT}

This study aims to evaluate the use of the Breakthrough Series Collaborative methodology in a Swedish county council improvement program, comparing measurements at the beginning and after six months. A questionnaire was used, and improvement processes and outcomes were analysed. The results showed an overall large engagement in improvements, although the methodology and the facilitators were seen as only moderately supportive. Nurses could play an active role in improving healthcare practices and patient safety.

Key words: Breakthrough Series Collaborative, Improvement evaluation, Nursing staff, Quality Improvement, Swedish healthcare organization

Quality improvement (QI) initiatives have increased within the health care sector in recent decades. 1 These efforts to improve quality can be seen as a response to demands for more cost-effectiveness, better medical results and improved patient safety. However, studies have shown that less than $40 \%$ of these initiatives are successful. The reason why specific improvement initiatives in health care fail or succeed is a central question in studies of change. 3 The need for more evidence about how to organize and manage new quality initiatives is therefore identified as an important task within studies of health care improvement. 2, 3, 4 Worldwide, different quality improvement collaboratives (QICs) are used to improve quality in health care. 5, 6, 7 In Swedish health care, many improvement initiatives use the Breakthrough Series Collaborative methodology, developed by the Institute for Healthcare Improvement (IHI) in Boston. 8 The methodology was introduced in Swedish health care by the Swedish Association of Local Authorities and Regions (SALAR). 9 Despite 
2013-03-20 review 1 språkgranskad

the fact that the method has been practiced for some time and seems to be applied extensively in many health care systems, critical examinations of its use and application are rare. 1, 3, 10 This study aims to empirically evaluate the use of the Breakthrough Series Collaborative improvement methodology in a county council improvement program, in order to contribute to the knowledge of the impact of quality improvement collaborative on improvement processes in Swedish health care.

\section{BACKGROUND}

\section{The Breakthrough Series Collaborative methodology}

The Breakthrough Series Collaborative methodology was developed in 1995 by the Institute for Healthcare Improvement (IHI) in Boston. 11 The developers' reasons were to reduce the gap between knowledge and practice, based on the insight that we can learn more and improve faster using collaboration than working alone. The quality improvement methodology is based on a structure in which health care teams from various organizations create a joint learning experience and use small-scale, rapid tests of change. Teams from different areas, sharing a common problem, join in collaboration, sharing ideas and best practice, aiming to speed up the pace of improvement in health care settings. There are eight key concepts that define the Breakthrough Series Collaborative. These are: 1) Plan-Do-StudyAct cycles are used to test and implement changes; 2) Anyone can have and test ideas; 3) Consensus is not needed to test an idea; 4) Change happens at all levels (not only at or from the top); 5) All teams are required to address all of the framework components simultaneously; 6) Ideas are stolen shamelessly; 7) Successes are spread quickly; 8) Measurement is for improvement, not research. The framework aims to identify key components of an ideal system based on existing best practice and evidence, breaking the 
system down into manageable parts and allowing focus on specific aspects within the system. 4, 7

A recent Norwegian study found three factors that were essential for continuous improvements to succeed in health care. 12 These were: reliable information and measurements, the engagement of everyone involved, and a culture built on improvement knowledge. Therefore, it is troublesome that there are recently trained nurses, in a large study in the US, who declare that they have never heard of QI, or at least feel poorly prepared in that area after their education. 13 An evaluation identified seven attributes that leaders thought were important for successful collaborations. 6 The important attributes were sponsorship and support, project topic, the team's ideas, the participants, management support, learning and practical work, and learning strategies about improvement knowledge. The respondents were pleased with the advantages of the collaborative methodology. At the same time the review of Wensing, Wollersheim and Grol points out that the benefits and underlying evidence of different quality management approaches are sometimes vague. $10 \mathrm{~A}$ report from a workshop evaluating sustainability in improvement projects in Sweden stated that there are numerous factors influencing improvements to be aware of. 3 The report suggested ten steps that could facilitate sustainability of improvements. Two of these are letting teams choose problems which are important to the professionals and patients, and ensuring that personnel understand the methods to be used.

\section{The empirical context- the county council improvement program}

The county council providing the data in the present study is one of 21 county councils and regions in Sweden. The county council quality improvement initiative started in 2007 and was a political investment with the vision and aim to become a learning organization with the welfare of patients in focus. The initiative is implemented both from the top management 
level and at individual departments/clinics/primary health care centres. The county council official management and the development department were assigned to implement this political decision. All healthcare departments, primary healthcare centres, dental clinics and other units in the county council were invited to accomplish improvement projects. The improvement initiative is described on the county council website (in Swedish). 14

Within the county council-wide improvement initiative, there are several efforts going on. There are two main strategies. 1) Project applications, in which participants could freely choose a method, sending a project application to a steering committee that considers the applications and recommends to the decision-making board which ones to approve and why. 15 2) Methodology-steered improvement programs based on the Breakthrough Series Collaborative, inviting staff teams to work with an innovation idea in a program using the Breakthrough Series Collaborative methodology with support from supervisors/facilitators. These facilitators are development staff working in the county council. Before the improvement program started these facilitators were educated in the Breakthrough methodology. The county council has made some local adjustments, but generally they have followed the concept from IHI. 8 As of autumn 2010 six of these programs have been started, involving about 130 teams and 610 staff members, the latest including staff and teams from some of the municipalities within the county council. Generally, the improvement ideas raise issues about patient safety, availability, effectiveness, and education/training. The aim of the present study was to empirically evaluate improvement processes using the Breakthrough Series Collaborative improvement methodology in a Swedish health care context, i.e., in a county council improvement program, comparing the results from the first measurement at the beginning of the Breakthrough improvement program with a second measurement six months later. 


\section{METHOD AND MATERIAL}

The study was designed as a longitudinal repeated survey study, and a questionnaire was used. 16 The Swedish Improvement Measurement Questionnaire (SIMQ) consisted of two dimensions, Improvement Effectiveness Outcome (three items) and Internal Improvement Processes (24 items, divided into eight sub-dimensions). The questionnaire was developed and psychometric properties were investigated. 16 The Improvement Effectiveness Outcome dimension had a Cronbach’s alpha coefficient of 0.67, and the Internal Improvement Processes had an overall Cronbach's alpha coefficient for the complete dimension of 0.72. 16 All items are shown written out in Table 1 (see Supplemental Digital Content, Table 1). In addition demographic and background items were included, such as time spent on improvement work and experience in the profession. In connection with some items there was a possibility to add comments.

\section{Participants and data collection}

The present study contains data from two improvement programs, running from September 2009 through November 2010. The participating employees within the county council ( $n=171)$ and the municipalities ( $n=39)$, a total of 210 participants, received the questionnaire. Most participants were nurses (see Supplemental Digital Content, Table 2). Data from the first measurement, at the beginning of the improvement program, and a second measurement six months later, after the improvement program ended, were analysed. The participants received written and verbal information from the first author at the regular improvement program meetings. The questionnaire was entered into a web-based survey program, EsMaker@, and was sent by e-mail to all participants. The informants consented by answering the web-based questionnaire. After one week and two weeks reminders sent automatically to those who had not answered. The alternative of getting the questionnaire as a paper copy was 
2013-03-20 review 1 språkgranskad

offered, but none were requested. The survey study was conducted according to general ethical standards and approved by the Regional Ethical Review Board in Linköping, Sweden (Dnr 179-09).

\section{Data analysis}

Data were analyzed using Statistica version 8.0 (StatSoft, Tulsa, OK, USA). Descriptive statistics are presented as actual frequencies, percentages, mean values, range and standard deviation (SD) and repeated measurements are presented as actual frequencies, percentages and mean values. Mean values above 2 are considered positive and below 2 negative. Differences are analysed using Wilcoxon Match Pairs test since the same participants' answers are compared between the two measurements. The participants' comments were compiled and the most frequent are shown.

\section{RESULTS}

\section{Participants}

Of the participants included in this study (i.e., answered both measurements $[n=41]$ ), the age range was 24-63, mean age 44 (SD 10.8) years. The majority, 80\% $(n=33)$ were women and $39 \%(n=16)$ were nurses. The participant experience in the profession ranged from $0.5-41$ years, with the mean of 15.9 (SD 12.3) years. The largest difference between the participants answering only the first measurement and those answering both the first and second measurement was in the number of nurses; it decreased to almost half as many in the second measurement. There was also a significant difference in working years. Those who answered only the first measurement had a mean working time experience of 21.8 years while the mean time was 15.9 years in the second measurement. Demographic data about the participants 
2013-03-20 review 1 språkgranskad

were analysed and compared between the two groups, using t-test and chi2 test (see Supplemental Digital Content Table 2).

\section{Background data}

In the first measurement the time spent on work with the improvement idea ranged from 3 to 80 hours (see Supplement Digital Content, Table 3). Most of the time was spent on the participant's own education, like the joint seminars learning the methodology; the second most time was spent on planning and administration. Administrative work was the only issue that all participants spent some time on. Least time, 7 minutes on average, was spent on acquiring economic funds and resources. In the second measurement, the time spent on working with the improvement idea ranged from 0 to 40 hours, in mean a decrease to about half the time spent. Most time was spent on planning and administration, followed by own education. Least time was still spent on acquiring economic funds and resources, only 2 minutes on average (see Supplement Digital Content, Table 3). In terms of experience with improvement work, $40 \%(n=16)$ stated that they had little or no earlier experience working with improvements, while $31 \%(n=13)$ had some and $29 \%(n=12)$ had quite a bit or a lot of experience. Earlier experience was both with improvements generally or in this special improvement program. At the same time $51 \%(n=21)$ of the respondents had no education in improvement work beforehand, 35\% $(n=14)$ had participated in other courses or training, $10 \%$ $(n=4)$ stated they had a university or college-level education, and 5\% $(n=2)$ had some other education, e.g. had participated in other improvement programs.

\section{Improvement Effectiveness Outcome}

The three items in this dimension all showed positive mean values at both measurements (see Supplemental Digital Content Table 1). The result showed that the majority of the 
respondents were satisfied with their work and what they had accomplished. The satisfaction had decreased in the second measurement although the difference was not significant.

The progress was above the respondents' expectations, increasing between the measurements, however not significant. A majority of the respondents thought that the improvement idea contributed to improving the work at the unit, increasing between the measurements, but not significant. In both measurements, only one respondent answered that the improvement idea did not contribute at all.

\section{Internal Improvement Processes}

The dimension Internal Improvement Processes consisted of eight sub-dimensions (see Supplemental Digital Content, Table 1). Both items measuring Innovation uncertainty showed positive mean values, in both measurements, although problems did arise significantly more often in the second measurement. The items about Resource scarcity affected the work with the improvement idea differently. A majority of the respondents $(73 \%, n=30$, first and second measurement respectively) stated that they had to compete for time to work with the improvement idea, showing almost equal mean values at first and second measurement. The last item, “Time to work with the improvement idea", showed low mean values at both measurements. The item "To what extent is your work on the improvement idea supported by the methods used in the improvement program?”, i.e., whether the use of the Breakthrough Series Collaborative Improvement methodology supported the work, was most often answered "Moderate" in both measurements. There were free comments about methods of measurements and how to show results. Need for evaluations and assessments to show improvements and distribute achieved results to other colleagues not involved were commented on. Suggestions on improving the work were about need to get more knowledge and use unit development days to work with improvements. 
The Improvement group leadership sub-dimension showed positive mean values in all but one measurement. The item about receiving feedback from the support personnel showed that the feedback decreased between the two measurements (see Supplemental Digital Content, Figure 1). The difference was significant ( $p$ 0.000). Also, the item about leader encouragement significantly decreased between measurements. The improvement program was finished when the second measurement was done. There were comments about manager support, such as wanting more help from managers to plan time for the team to meet. Others commented on clearer project leadership and more response from project (team) leaders. The Freedom to express doubt and Learning encouragement sub-dimensions both showed that the participants thought they could be critical about the work with the improvement idea, and even fail, without harming their future career at the organization they worked in. At the same time, the item “The county council prioritizes experimenting with new ideas” showed negative mean values.

\section{DISCUSSION}

The aim of this study was to empirically evaluate improvement processes in an improvement program using the Breakthrough Series Collaborative methodology in Swedish health care settings. The item of whether the methodology supports the work was mostly scored "Moderate" showing slightly positive mean values. At the same time a rather large number responded that they did not receive enough feedback from the improvement program facilitators (see Supplemental Digital Content, Figure 1). There is a facilitation support organisation built up at local (administration) levels to be able to support improvement work going on at different levels in the organisation, made up of organization developers, mainly nurses having working experience of improvements. Discussing those findings with those 
facilitators, they claimed that at the second measurement six months later the methodology program was ended. One can assume that the respondents' answers only concern the support during the program, and then this result will be understandable and correspond to the explanation of the facilitators.

\section{Improvement skills}

The answers that the methodology does not support the work properly are more problematic. Are the instruments too complicated, not introduced properly or simply not regarded as sufficient? There are many health care organisations worldwide using the Breakthrough Series Collaborative. 8 There is only one evaluation made in Sweden that we are aware of, and this report stated that the most important factor for those programmes to succeed in the long term is that the organisations can make use of the knowledge that the teams have accomplished after the program has ended. 3 The importance of introducing improvement skills in different health care educations has been highlighted lately, however. 17, 18, 19, 20 One of the core competencies stated for nurses is quality improvement, 20, 21, and the Quality and Safety Education for Nurses (QSEN) initiative has worked with the issue for almost a decade. 18, 20 So, even if this study shows nurses as the largest group participating in improvement work, there is more that the nursing profession could do. The results in the present study suggest that more established team leadership would support the improvement work. Even if the participants were aware of their responsibilities and thought that the project leader had confidence in them, there were some comments about response and encouragement from project leaders, wanting clearer project leadership. One of the core competencies for nurses is teamwork. 20, 21 Therefore, it could be a question of nurses leading those improvement teams.

\section{Satisfaction and commitment}


Some interesting findings are the overall satisfaction with the improvement work and the awareness of individual responsibilities, as well as the feeling of openness, to express what you think about the work. Ekvall describes this in terms of the organisation's climate, implying a certain degree of openness, commitment, motivation and risk-taking mentality. 22 The more positive the climate is, the more innovative the organisation will be and employees more satisfied. He also claims that risk taking, dynamism and freedom play a role in creating an innovative organisation. Clancy argues that slow response to improvement efforts in organizations is due to a culture that is deeply embedded and hard to change. 23 In our study the items concerning decision-making influence do not show this. But the awareness of the individual responsibility as well as the item about commitment can be factors having an influence on satisfaction. Kvist et al. emphasize the importance of encouraging staff participants. They can not be managed to improve; managers need to motivate them to use their knowledge and abilities in the best way. 24

The comparison between the participants showed that nurses were the largest group not answering the second time (see Supplemental Digital Content, Table 2). There are different reasons for not participating in a survey. Responses from participants indicated that there are many surveys circulating in health care, which could be one reason why some of the respondents chose not to complete the questionnaire.

Respondents stated that they had to compete for time, which applies to the comments about lack of time. The respondents thought that they needed scheduled time so the whole team could meet and work together. The ordinary daily work always intruded. The time issue is supported by the fact that 52\% (first measurement) stated that they had to compete for time to work with the improvement idea. But at the same time, most respondents were satisfied with 
what they had accomplished, and thought their work was useful to the unit and to the health care organization.

The fact that $62 \%$ (first measurement) stated that they did not have to compete for attention from management (executive level) is interesting. At the same time a recurring comment was about wanting more attention and support from management. This can be somewhat confusing, but, perhaps one important factor in improvement work is to what degree the staff can influence the work. Both Kvist et al. 24 and Zrelak et al. 25 raise the notion that possibilities to influence and make decisions about work are important. Increasing the impact nurses have on quality initiatives increases the possibility that system changes will succeed.

\section{LIMITATIONS}

The sample size in this study is rather small, which is a weakness. The response rate answering both measurements was only $n=41$. But, as stated by Wensing, Wollersheim and Grol, among others, there are needs to evaluate improvement efforts. 10 Another weakness could be that data are self-reported. The respondents answer a questionnaire. It is hard to find other, more objective measurements to evaluate these kinds of improvement efforts, and surveys are frequently used in health care research. 16

\section{CONCLUSIONS}

This paper was the first analysis of data following an improvement program using the Breakthrough Series Collaborative methodology in a Swedish county council. Although the sample size is small, there are some indications on important factors that could increase the chances that improvement processes following Breakthrough Series Collaborative programs will be successful. Time to work with the improvement idea seems to be an important and 
2013-03-20 review 1 språkgranskad

difficult factor. Teams need time together and sometimes they express the feeling of making time "legal" to work with improvements instead of regular tasks. The time is connected to the next factor identified: management support. Managers need to support the work more explicitly. This would also give the work the legitimacy that the respondents are asking for. The third factor identified is that the Breakthrough method is regarded as difficult and not always supportive of the work. Whether this is due to insufficient support from facilitators is not clear. Seeing that the respondents wish to get more feedback from the support personnel, the fourth factor identified, perhaps this is one way to make it easier to use the method. One of the ideas in using the Breakthrough methodology is to spread improvement knowledge, learning from and with each other, so this is an important finding. A solution suggested by nursing educators is to incorporate improvement knowledge in nursing education. 17, 18, 20 Nurses are the largest profession within health care, mainly with a high emphasis on patient safety. For that reason improvements is an issue that nurses could influence positively.

Figure 1. Receiving feedback.

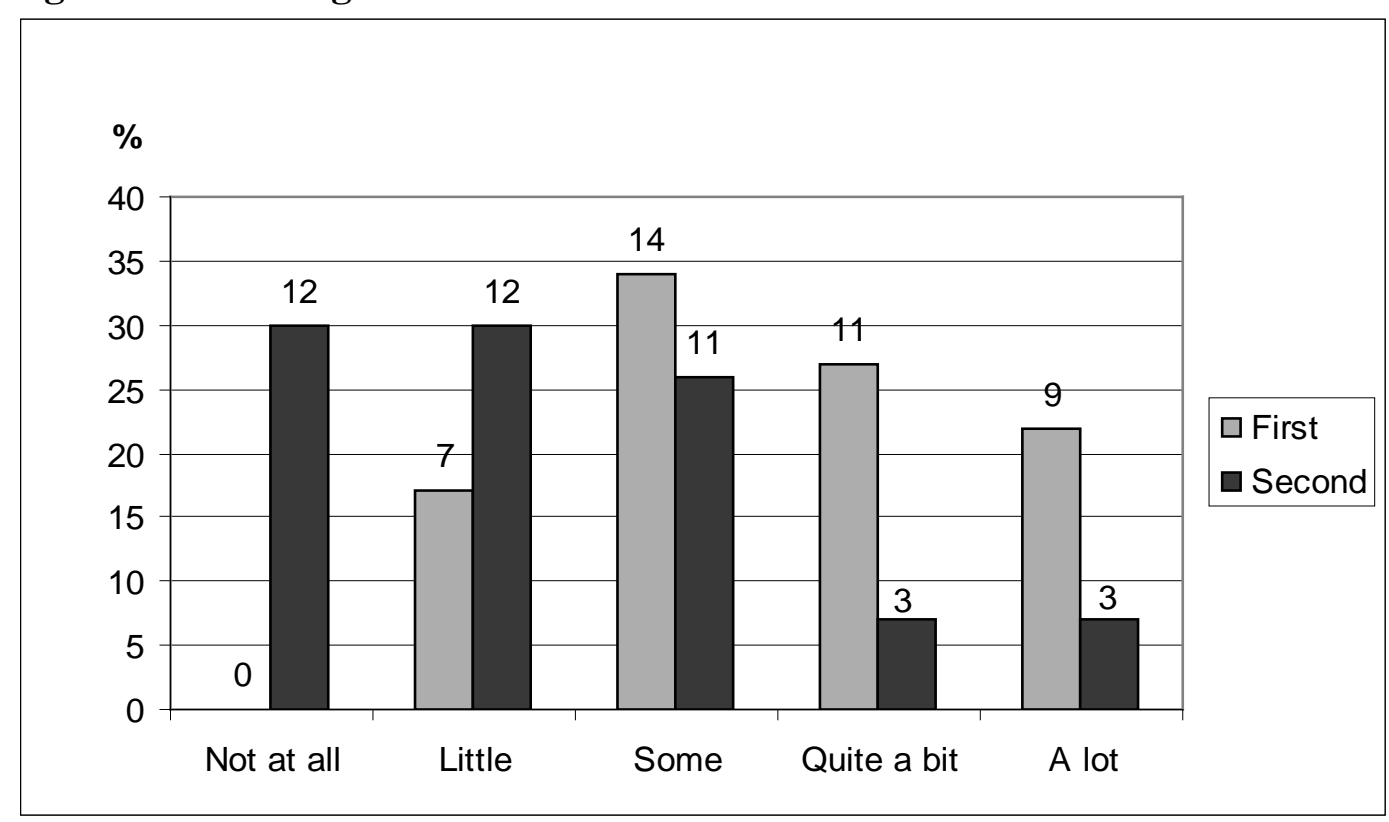

Answers to the question: "Do those involved in working with the improvement idea receive feedback on how to improve their work?” Figures in the graph are actual frequencies $(n=41)$. 
Table 1. The Swedish Improvement Measurement Questionnaire (SIMQ).

Items and mean value first and second measurement.

\begin{tabular}{lr}
\hline Improvement Effectiveness Outcome (n=41) & $\begin{array}{c}\text { Mean } \wedge \\
\text { first / } \\
\text { second }\end{array}$ \\
\hline $\begin{array}{l}\text { 1. Overall, how satisfied are you with the progress that has been made in the work } \\
\text { to develop the improvement idea during the past month? }\end{array}$ & $3.0 / 2.7$ \\
$\begin{array}{l}\text { 2. To what extent is your progress with the improvement idea below or above your } \\
\text { original expectations? }\end{array}$ & \\
$\begin{array}{l}\text { 3. How much does the improvement idea contribute to improving the work at your } \\
\text { unit? }\end{array}$ & $2.4 / 2.5$ \\
\hline
\end{tabular}

Internal Improvement Processes (8 sub-dimensions)

Innovation uncertainty $(\mathrm{n}=41)$

4. How easy is it for you to know ahead of time what steps are necessary to

develop the improvement idea?

5. How often in the past month did problems arise during development of the improvement idea?

Resource scarcity $(\mathrm{n}=41)$

How much must your improvement idea compete with other activities within your unit, when it comes to

6a. Economic resources?

6b. Material, space, and equipment?

6c. Attention from the executive level?

$2.7 / 2.6$

6d. Personnel?

$2.4 / 2.6$

$6 e$. Time to work with the improvement idea?

Standardization of procedures $(n=41)$

7. To what extent is your work on the improvement idea

supported by the methods used in the improvement program?

$2.3 / 2.2$

Expectations of Rewards and Sanctions $(\mathrm{n}=41)$

How likely is it that the following will occur if the goals of the improvement idea have been achieved:

8a. Everyone involved, as a group, will be rewarded or recognized for their

collective efforts.

8b. Only some participants will be rewarded or recognized for their individual

$3.4 / 3.4$ efforts.

How likely is it that the following will occur if the goals of the improvement idea have not been achieved:

9a. Everyone involved, as a group, will be reprimanded or told to "shape up" to improve their efforts.

9b. Only some participants will be reprimanded or told to "shape up" to improve their efforts.

Improvement Group Leadership $(\mathrm{n}=41)$

10. The project leader of the improvement idea encourages the participants to take initiative.

11. The participants involved in the improvement idea are aware of their individual responsibilities.

12. The project leader for the improvement idea places great emphasis on getting 
the work done.

13. The project leader has great confidence in the participants involved in the improvement idea.

14. Do those involved in working with the improvement idea receive feedback from "improvement support"/their supervisor on how they can improve their work? $2.5 / 1.3$ * Freedom to Express Doubts $(\mathrm{n}=41)$

15. To avoid causing disharmony I often feel I cannot say what I think about the work on the improvement idea.

\section{Learning Encouragement ( $\mathrm{n}=41$ )}

16. If a colleague tries something new and fails, this is viewed as something that

could harm her/his future career in the county council.

17. The county council prioritizes experimenting with new ideas.

\section{Decision Influence **}

How much influence have you had on each of the following decisions that might have been made during the past month?

18a. Preparing goals and measures for the improvement idea? $(n=29)$

18b. Deciding which activities should be carried out within the improvement idea? $(\mathrm{n}=35)$

18c. Deciding on economic funds and resources for the improvement idea? $(n=26)$

$18 \mathrm{~d}$. Recruiting colleagues to work with the improvement idea? $(\mathrm{n}=25)$

$\wedge$ Mean values above 2 are considered positive and below 2 negative.

* Wilcoxon Match pairs, $\mathrm{p}<0.05$.

** Answer alternative "No decision made" is excluded from mean value calculations.

Table 2. Participant background characteristics and drop out analyse.

Differences between participants answering only first measurement and those answering both first and second measurement.

\begin{tabular}{|c|c|c|c|}
\hline & $\begin{array}{l}\text { Only first } \\
\text { measurement } \\
(\mathrm{n}=51) \\
\mathrm{n}(\%)\end{array}$ & $\begin{array}{l}\text { Both first and } \\
\text { second measurement } \\
(\mathrm{n}=41) \\
(6 \text { months between) } \\
n(\%)\end{array}$ & p value \\
\hline Professions & & & \\
\hline Physician & $4(8)$ & $5(12)$ & n.s. $†$ \\
\hline $\begin{array}{l}\text { Nurse (including midwife/ } \\
\text { other specialities) }\end{array}$ & $30(59)$ & $16(39)$ & $.05(\mathrm{df} 2) \dagger$ \\
\hline Assistant nurse & $6(12)$ & $3(7)$ & n.s. $\dagger$ \\
\hline Other $*$ & $11(21)$ & $17(42)$ & n.s. $\dagger$ \\
\hline \multicolumn{4}{|l|}{ Gender } \\
\hline Men & $7(14)$ & $8(20)$ & n.s. $\dagger$ \\
\hline Women & $44(86)$ & $33(80)$ & n.s. $†$ \\
\hline Age: mean & 48 & 44 & n.s. $\wedge$ \\
\hline
\end{tabular}


range, (SD)

\section{Professional experience}

(year):

mean, range, (SD)
28-63 $(9,1)$

21,8

2-41 $(11,2)$
24-63 $(10,8)$

15,9

$0.017 \wedge$

* Others, e.g. medical secretaries, physiotherapists, occupational therapists, dieticians, psychologists and audiologists

$\dagger$ chi2 test

$\wedge$ t-test

Table 3. Time spent on different activities working with the improvement idea.

\begin{tabular}{|c|c|c|}
\hline Statement & $\begin{array}{c}\text { First } \\
\text { Measurement } \\
\text { Mean value } \\
\text { Min/max value } \\
\end{array}$ & $\begin{array}{c}\text { Second } \\
\text { measurement } \\
\text { Mean value } \\
\text { Min/max value } \\
\end{array}$ \\
\hline $\begin{array}{l}\text { On average during the past month, how } \\
\text { many hours did you work on issues } \\
\text { related to the improvement idea? }\end{array}$ & $\begin{array}{l}\text { 13h } 32 \mathrm{~min} \\
3 \mathrm{~h} / 80 \mathrm{~h}\end{array}$ & $\begin{array}{l}\text { 5h } 34 \mathrm{~min} \\
0 / 40 \mathrm{~h}\end{array}$ \\
\hline \multicolumn{3}{|c|}{$\begin{array}{l}\text { Of this time during the past month, approximately how } \\
\text { many hours were spent on each of the following activities: }\end{array}$} \\
\hline $\begin{array}{l}\text { Supervising colleagues involved in the } \\
\text { improvement idea? }\end{array}$ & $\begin{array}{l}\text { 1h } 22 \mathrm{~min} \\
0 / 30 \mathrm{~h}\end{array}$ & $\begin{array}{c}34 \mathrm{~min} \\
0 / 2 \mathrm{~h}\end{array}$ \\
\hline $\begin{array}{l}\text { Working with or developing } \\
\text { measurement methods for the } \\
\text { improvement idea? }\end{array}$ & $\begin{array}{l}\text { 2h } 22 \mathrm{~min} \\
0 / 10 \mathrm{~h}\end{array}$ & $\begin{array}{c}14 \mathrm{~min} \\
0 / 2 \mathrm{~h}\end{array}$ \\
\hline $\begin{array}{l}\text { Discussing the improvement idea with } \\
\text { potential users or customers/patients? }\end{array}$ & $\begin{array}{l}\text { 1h } 23 \min \\
0 / 15 h\end{array}$ & $\begin{array}{c}46 \mathrm{~min} \\
0 / 5 \mathrm{~h}\end{array}$ \\
\hline $\begin{array}{l}\text { Acquiring economic funds and resources } \\
\text { for the improvement idea? }\end{array}$ & $\begin{array}{l}7 \min \\
0 / 2 \mathrm{~h}\end{array}$ & $\begin{array}{c}2 \mathrm{~min} \\
0 / 1 \mathrm{~h}\end{array}$ \\
\hline Coordinating the improvement idea with & $48 \mathrm{~min}$ & $45 \mathrm{~min}$ \\
\hline
\end{tabular}


2013-03-20 review 1 språkgranskad

other units or departments?

Preparing to summarize and report on the improvement idea?

Administrative work (planning, paperwork)?

Personal education (reading and seminars to keep myself updated)?

$\begin{array}{cc}\text { 0/6h } & 0 / 6 \mathrm{~h} \\ \text { 2h } 15 \mathrm{~min} & 34 \mathrm{~min} \\ 0 / 10 \mathrm{~h} & 0 / 3 \mathrm{~h} \\ 3 \mathrm{~h} 4 \mathrm{~min} & 1 \mathrm{~h} 41 \mathrm{~min} \\ \text { 30min/15h } & 0 / 10 \mathrm{~h} \\ 3 \mathrm{~h} 15 \mathrm{~min} & 58 \mathrm{~min} \\ 0 / 24 \mathrm{~h} & 0 / 25 \mathrm{~h}\end{array}$




\section{REFERENCES}

1 Dückers MLA, Spreeuwenberg P, Wagner C, Groenewegen PP. Exploring the black box of quality improvement collaboratives: modelling relations between conditions, applied changes and outcomes. Implement Sci. 2009;4(74). doi:10.1186/1748-5908-4-74. Accessed November 20, 2012.

2 Olsson J, Elg M, Lindblad S. System characteristics of healthcare organizations conducting successful improvements. J Health Organ Manag. 2007;21(3):283-296.

3 Øvretveit J. Making temporary quality improvement continuous: A review of research relevant to the sustainability of quality improvement in health care. 2003. http://www.skl.se/vi_arbetar_med/halsaochvard/kvalitetsutveckling/genombrott/projektle darutbildning/forskning_och_utvardering_1. Accessed November 20, 2012.

4 Walshe K. Pseudoinnovation: the development and spread of healthcare quality improvement methodologies. Int J Qual Health Care. 2009;21(3):153-159.

5 Øvretveit J, Bate P, Cleary P, Cretin S, Gustafson D, McInnes K, McLeod H, Molfenter T, Plsek P, Robert G, Shortell S, Wilson T. Quality collaboratives: lessons from research. Qual Saf Health Care. 2002;11(4):345-51.

6 Wilson T, Berwick DM, Cleary P.D. What Do Collaborative Improvement Project Do? Experiences from Seven Countries. Jt Comm J Qual Saf. 2003;29(2):85-93.

7 Shaw EK, Chase SM, Howard J, Nutting PA, Crabtree BF. More Black Box to Explore: How Quality Improvement Collaboratives Shape Practice Change. J Am Board Fam Med. 2012;25(2):149-157. 
8 Institute for Healthcare Improvement. (2003). The Breakthrough Series: IHI's Collaborative Model for Achieving Breakthrough Improvement, Innovation Series White Paper. http://www.ihi.org. Accessed November 19, 2012.

9 Swedish Association of Local Authorities and Regions (SALAR) website. http://www.skl.se/. Accessed November 19, 2012.

10 Wensing M, Wollersheim H, Grol R. Organizational interventions to implement improvements in patient care: a structured review of reviews. Implement Sci. 2006;1(2). doi:10.1186/1748-5908-1-2. Accessed November 20, 2012.

11 Institute for Healthcare Improvement (IHI) website. http://www.ihi.org. Accessed November 20, 2012.

12 Skard Brandrud A, Schreiner A, Hjortdahl P, Saevil Helljesen G, Nyen B, Nelson EC. Three success factors for continual improvements in healthcare: an analysis of the reports of improvement team members. BMJ Qual Saf. 2011;20(3):251-259.

13 Kovner CT, Brewer CS, Yingrengreung S, Fairchild S. New nurses' views of quality improvement education. Jt Comm J Qual Patient Saf. 2010;36(1):29-35.

14 Kvalitetswebben (in Swedish). http://www.ltkalmar.se/lttemplates/SubjectPage_2226.aspx. Accessed November 20, 2012.

15 Andersson A-C, Elg M, Idvall E, Perseius K-I. Five Types of Practice-Based Improvement Ideas in Health Care Services: An Empirically Defined Typology. Qual Manag Health Care. 2011;20(2):122-130.

16 Andersson A-C, Elg M, Perseius K-I, Idvall E. Evaluating a revised survey to measure improvement initiatives in Swedish healthcare. BMC Health Serv Res. 2013;13(48). doi: 10.1186/1472-6963-13-48. Accessed Mars 24, 2012. 
2013-03-20 review 1 språkgranskad

17 Institute of Medicine (IOM). The Future of Nursing: Leading Change, Advancing Health. The National Academy Press, 2011.

http://www.nap.edu/catalog.php?record_id=12956. Accessed January 25, 2013.

18 Armstrong G, Headrick L, Madigosky W, Ogrinc G. Designing Education to Improve Care. Jt Comm J Qual Patient Saf. 2012;38(1):5-14.

19 Institute of Medicine (IOM). Crossing the Quality Chasm: A New Health System for the 21st Century. National Academies Press, 2001. http://www.nap.edu/catalog/10027.html. Accessed January 25, 2013.

20 Sherwood G, Barnsteiner J. (eds.) Quality and Safety in Nursing: A Competency Approach to Improve Outcomes. Wiley-Blackwell, 2012.

21 Svensk Sjuksköterskeförening (SSF). Strategi för utbildningsfrågor (in Swedish). 2010. http://www.swenurse.se/Documents/Publikationer\%20pdf-

filer/Strategi\%20f\%c3\%b6r\%20utbildnfr\%c3\%a5gor.pdf. Accessed January 25, 2013.

22 Ekvall G. Organizational Climate for Creativity and Innovation. Eur J Work Organ Psychol. 1996;5(1):105-123.

23 Clancy CM. New Research Highlights the Role of Patient Safety Culture and Safer Care. J Nurs Care Qual. 2011;26(3):193-196.

24 Kvist T, Vehviläinen-Julkunen K, Jokela V. Do Organizational Factors Explain the Quality of Care? J Nurs Care Qual. 2007;22(4):365-370.

25 Zrelak PA, Utter GH, Sadeghi B, Cuny J, Baron R, Romano PS. Using the Agency for Healthcare Research and Quality Patient Safety Indicators for Targeting Nursing Quality Improvement. J Nurs Care Qual. 2011;27(2):99-108. 